\title{
Die herhaalde verskyning van transendensie in verskeie kulturele fenomene
}



Hierdie boek is deel 42 in die reeks Currents of Encounter: Studies on the Contact between Christianity and Other Religions, Beliefs, and Cultures en bring inderdaad belangrike raakvlakke in hierdie gesprek na vore. Skeptici sal egter dadelik wonder of dit die moeite werd is om in hierdie post-transendente, post-metafisiese tyd hernude aandag aan transendensie te skenk. Dit word egter gou duidelik dat transendensie voortdurend nuut verstaan en herinterpreteer word, dat die grense daarvan - binne die filosofie, teologie, kuns en politiek - aanhou verskuif soos wat die subtitel Looking Beyond? tereg aandui. Hierdie verskuiwings word genoodsaak deur die talle veranderinge in ons Westerse kultuur, soos sekularisasie, 'n groter wordende tegno-wetenskaplike wêreldbeskouing, nuwe verstaan van tyd en ruimte (kosmologie), nuwe ontwikkelings in biologie, kognitiewe en breinwetenskappe, sowel as nuwe filosofiese idees. In ' $n$ post-transendente, post-metafisiese tyd is die vraag dus nie net eenvoudig wat het transendensie vervang nie, maar eerder hoe het die grense van transendensie verskuif en hoe word dit nuut verstaan.

Hierdie vrae word deur Stoker en Van der Merwe in die boek gevra, en 'n omvangryke antwoord word by monde van die verskillende skrywers daarop gegee. Oor die belang van die konsep transendensie sê Stoker en Van der Merwe dat die beter verstaan daarvan 'n mens kan help om skuiwe in die verskillende dimensies van ons kultuur beter te verstaan. Hulle gaan van die aanname uit (sien die voorwoord van Looking Beyond) dat die kontemporêre religieuse en spirituele landskap van ten minste die gesekulariseerde Weste baie helder na vore kan kom as daar gefokus word op die breuke en parallelle tussen die 'gloeiende spore' wat deur die voortdurende verskynings van transendensie, wetend of onwetend, in die werke van verskeie skrywers oor sekere kulturele fenomene nagelaat is. Met Stoker se aanbieding van 'n tipologie van transendensie (as inleiding tot die boek), word 'n analitiese, heuristiese stuk gereedskap gebied waarmee hierdie skuiwe ondersoek kan word. Die doel daarvan is om insig te kry in ons kultuur, wat weer lei tot insig oor ons eie lewe of denke en die vorming daarvan.

Die boek bestaan uit ses hoofdele waarin altesaam sewe-en-twintig gesiene akademici van Europa, Noord-Amerika en Suid-Afrika meegewerk het. Die eerste deel handel oor Filosofie: Historiese Benaderings en Danie Goosen wys hier byvoorbeeld op die probleem van radikale immanensie in die 'geskiedenis van idees'. Die tweede deel fokus op Kontemporêre Filosofie en hierin skryf Annemie Halsema oor Humanisme en Transendensie en Pieter Duvenage oor Vroeë Kritiese Teorie en Habermas oor Transendensie. Die derde deel bespreek Filosofiese Teologie en Schalk Engelbrecht en Willie van der Merwe bespreek hier onder andere Gianni Vattimo se werk as 'Transendensie en (Postmetafisiese) Utopia'. Deel vier oor Christelike Filosofie sluit besprekings deur bekende teoloë soos Sally McFague en Mark Taylor in. In deel vyf gaan dit oor Politiek en Vasti Roodt fokus byvoorbeeld op Hanna Arendt se filosofie in haar essay oor ' $n$ Politiese Teologie van ' $n$ Afwesige God. Die laaste deel gaan oor Kuns en hier kom 'n wye verskeidenheid essays aan die orde. ' $n$ Interessante perspektief in hierdie deel is die essay, Momente van Transendensie in Kunsmatige Intelligensie (Moments of Transcendence in A.I.), van Heide de Mare waarin sy vra of transendensie 'n kunsmatige ervaring is wat geskep kan word deur beelde en klanke te manipuleer.

In die slotbetoog sê Willie van der Merwe dat daar met postmodernisme ' $n$ neiging weg van die transendente na die immanente is, maar dat transendensie nie eenvoudig 'verdwyn' nie. Die radikale immanensie laat weer nuwe vrae na vore kom. Is dit byvoorbeeld moontlik om verby ' $n$ ironie van transendensie in die radikale immanensie te beweeg - dit wat die probleem is by Deleuze se plat vlak van immanensie? Is radikale immanensie 'volhoubaar'? Watter implikasies het dit uiteindelik alles vir religie?

Die belang van transendensie in ons 'post-transendente tyd' is omvangryk. Die indringende vrae rondom die konsep is legio. Looking Beyond? is egter ' $n$ waardevolle rigtingwyser in hierdie soeke en die publikasie hiervan is uiters welkom en kan definitief verdere navorsing hieroor verryk. Die tipologie van transendensie van Stoker bied 'n helder vertrekpunt tot die gesprek. Die essays, wat in die boek saamgebundel is, spreek van deeglike navorsing en almal dra by tot die hoogstaande gehalte van die publikasie. Veral akademiese lesers (vanuit teologie, filosofie, politiek en kuns) sal aanklank by die boek vind. 